\title{
Light sensitivity in larval fishes: Implications for vertical zonation in the pelagic zone
}

\author{
Suresh D. Job and David R. Bellwood \\ James Cook University, Townsville, Queensland 4811, Australia
}

\begin{abstract}
Larval fishes exhibit marked vertical zonation patterns that are important in planktonic predator-prey interactions. This zonation has been related to both proximate physical (e.g., light intensity) and ultimate biological factors (e.g., predator risk, prey availability). We hypothesize that changes in visual sensitivity and feeding performance in larval fishes provide a constraint on depth distributions and that this constraint may represent the major determinant of vertical distribution patterns. To test the generality of the relationship between larval age and visual sensitivity, larvae were obtained from captive breeding adults of seven species (three Apogonidae and four Pomacentridae). The lowest light intensity at which feeding behavior occurred was measured using infrared video techniques with natural prey items. The visual sensitivity of the larvae, measured as initiation of feeding, increased by about 3 orders-of-magnitude during the larval phase. The abilities of the larvae were broadly similar within families, but there were marked differences between families. Pomacentrids were about an order-of-magnitude less light-sensitive than apogonids. Larval apogonids are potentially capable of feeding at a depth of about $100 \mathrm{~m}$ in clear tropical waters at $4 \mathrm{~mm}$ standard length (SL) and to $200 \mathrm{~m}$ at $12 \mathrm{~mm}$ SL. The patterns of ontogenetic and phylogenetic differences in light sensitivity are consistent with field observations on the vertical distributions of larvae in these taxa.
\end{abstract}

One of the most consistent patterns in open water marine and freshwater systems is the presence of vertical stratification in the structure of pelagic communities (Falkenhaug et al. 1997; Megard et al. 1997). This stratification is prominent in invertebrate zooplankton and ichthyoplankton. Most studies of vertical stratification in planktonic communities have focused on diel changes in vertical distribution (Neilson and Perry 1990; Dagg et al. 1997). However, planktonic organisms from a range of aquatic systems also display marked ontogenetic and taxonomic differences in diurnal vertical distribution patterns (Falkenhaug et al. 1997; Olivar and Sabates 1997; Williams and Koslow 1997). Interestingly, such taxonomic and ontogenetic differences in depth-distribution are generally less well understood than diel vertical migration patterns. Two broad sets of hypotheses have been proposed to explain the taxonomic and ontogenetic differences in vertical distributions.

One set of hypotheses invoke interactions between physical processes and plankton behavior. Current velocity (Boehlert et al. 1992), thermoclines (Haldorson et al. 1993; Williams and Koslow 1997), and light intensity (Blaxter 1988; Leis 1991a) have all been suggested as key physical factors that structure the vertical distribution of fish larvae. The role of light intensity has been the focus of most research. Substantial data suggest that light plays an important but different role in structuring vertical distribution patterns in invertebrate zooplankton versus ichthyoplankton (Munk et al. 1989; Falkenhaug et al. 1997; Gronkjaer and Wieland

\section{Acknowledgments}

This work was supported by the Australian Coral Reef Society, a James Cook University Merit Research Grant (SJ), and the Australian Research Council (DRB). JCU Experimentation Ethics Review Committee approval A202, A402. We thank R. Rowe, E. Drew, and J. Morrison for assistance with logistics and R. K. Cowen, J. Endler, M. Hixon, T. P. Hughes, J. M. Leis, J. N. Marshall, M. McCormick, J. Shand, and P. C. Wainwright for comments on the manuscript.
1997). While invertebrate plankters are able to use depth as a refuge during the day and rise to shallow waters to feed at night, larval fishes are predominantly visual feeders and require sufficient light to feed (Blaxter 1988; Gerking 1994). Larval fishes will, therefore, be limited in terms of maximum sustainable depths by the exponential decline in light intensity with water depth. The lower limit of larval fish vertical distributions may be set by the minimum light intensity at which feeding is possible. A second set of hypotheses invoke behaviors that minimize predation while maximizing feeding rates (Clark and Levy 1988; Fortier and Harris 1989; Nesbitt et al. 1996). Prey availability and predation risk appear to vary with depth and light intensity and with the ontogenetic stage, and size of the larvae (Fortier and Harris 1989; Munk et al. 1989; Litvak and Leggett 1992). A critical evaluation of these two sets of hypotheses cannot proceed without a clear understanding of the performance capabilities of the various planktonic animals. Differences in the performance capabilities of the plankters would influence both their behavioral responses to physical factors and the mechanisms available to them to maximize foraging success while minimizing predation.

Larval marine fishes represent an excellent group to assess the importance of feeding performance in structuring vertical distribution patterns. There are marked ontogenetic and taxonomic differences in the vertical distribution patterns of most larval fish taxa (Cowen et al. 1993; Haldorson et al. 1993; Olivar and Sabates 1997). It has been suggested that the vertical distribution of larval fishes may be a result of taxon-specific preferred light levels (Blaxter 1988; Leis $1991 a$ ). However, the proximate mechanism by which light interacts with larval behavior to influence vertical stratification remains unknown. As visual resolution and prey visibility vary with light intensity (Blaxter 1988; Utne 1997), light may act by affecting the ability of the larvae to detect and capture prey. Indeed, the combination of light intensity and prey density (= prey availability) may better predict lar- 
val fish distributions than prey density alone for some taxa (Gronkjaer and Wieland 1997). However, it fails to explain the taxonomic and ontogenetic differences in vertical distribution patterns.

Implicit in the predation risk and prey availability hypotheses is the assumption that larval fish are capable of feeding equally well at all depths and that the larval fish feeding abilities are consistent among fish taxa at a given light intensity. If the conflicting sets of hypotheses are to be evaluated, there is a clear need to understand the relationship between light levels and the prey capture abilities of larval fish. In the present study, the feeding performance of larval fish in relation to light intensity is measured directly, evaluating the role of ontogeny and taxonomic affinity in determining the feeding performance. The central question is: how does the relationship between light intensity and feeding performance of fish larvae vary with age and to what extent are the patterns taxon-specific? If the feeding abilities of fish larvae are comparable throughout the depth range occupied by larvae, then light may only indirectly influence larval distributions through modification of predator and prey distributions. However, if the visual abilities of fish vary markedly with light intensity, particularly if these abilities are dependent upon taxonomic affinity or ontogenetic stage, then light levels may provide a direct physical gradient that determines the maximum depth at which larvae of each taxa occur at a given developmental stage.

\section{Methods}

We established a larval rearing program to provide larval reef fishes from first feeding to settlement. This permitted direct measurement of the performance of key functional systems of larval reef fishes under controlled conditions throughout ontogeny. The experiments used natural prey under a light spectrum that closely replicated conditions in coral reef waters at approximately $20-30 \mathrm{~m}$ depth. We used the minimum light intensity at which feeding on natural prey commenced as the basis for evaluating the relative contribution of fish size, developmental age, and phylogeny on feeding performance. In order to examine interspecific differences in the feeding performance, seven species were examined: three cardinalfishes (Apogonidae: Apogon cyanosoma, A. compressus, Cheilodipterus quinquilineatus) and four pomacentrids (two damselfish, Pomacentrinae: Pomacentrus amboinensis, Neopomacentrus bankieri, and two anemonefish, Amphiprioninae: Premnas biaculeatus, Amphiprion melanopus). These species were drawn from two phylogenetically and ecologically distinct lineages. Adult pomacentrids are primarily diurnal zooplanktivores with the exception of $P$. amboinensis, which is broadly omnivorous. Adult $A$. cyanosoma and A. compressus are nocturnal planktivores, while adult $C$. quinquilineatus are primarily nocturnal piscivores. All of the study species are widespread and abundant on Indo-Pacific coral reefs.

Larvae were obtained from captive breeding adults and reared in 200 -liter glass aquaria at $28-30^{\circ} \mathrm{C}$ under a $14: 10$ light-dark photoperiod. The temperature and photoperiod are similar to conditions on the Great Barrier Reef lagoon during
Table 1. Developmental schedules of the seven study species at $28^{\circ}-30^{\circ} \mathrm{C}$.

\begin{tabular}{|c|c|c|c|}
\hline Species & $\begin{array}{l}\text { Egg } \\
\text { duration } \\
\text { (days) }\end{array}$ & $\begin{array}{l}\text { Age at } \\
\text { flexion } \\
\text { (days } \\
\text { post- } \\
\text { hatch) }\end{array}$ & $\begin{array}{c}\text { Larval } \\
\text { duration } \\
\text { (days } \\
\text { post- } \\
\text { hatch) }\end{array}$ \\
\hline \multicolumn{4}{|l|}{ Family Pomacentridae: } \\
\hline $\begin{array}{l}\text { Pomacentrus amboinensis } \\
\text { Neopomacentrus bankieri } \\
\text { Premnas biaculeatus } \\
\text { Amphiprion melanopus }\end{array}$ & $\begin{array}{l}4 \\
3 \\
7 \\
9\end{array}$ & $\begin{array}{c}5-7 \\
7-8 \\
3-5 \\
1\end{array}$ & $\begin{array}{c}18-19 \\
20-21 \\
9-10 \\
7-8\end{array}$ \\
\hline \multicolumn{4}{|l|}{ Family Apogonidae: } \\
\hline $\begin{array}{l}\text { Cheilodipterus quinquilineatus } \\
\text { Apogon cyanosoma } \\
\text { Apogon compressus }\end{array}$ & $\begin{array}{l}7 \\
4 \\
7\end{array}$ & $\begin{array}{l}4-6 \\
5-8 \\
7-8\end{array}$ & $\begin{array}{l}23-24 \\
23-24 \\
23-24\end{array}$ \\
\hline
\end{tabular}

the summer peak reproductive period. Larvae were reared using a modification of the techniques described in Job et al. (1997). Larvae were fed with freshly collected size-sorted wild-caught zooplankton throughout the larval stage to ensure that there was no conditioning to abnormal prey items (e.g., rotifers). Larvae below $3.5 \mathrm{~mm}$ standard length (SL) were fed zooplankton which were passed through a $125 \mu \mathrm{m}$ plankton sieve and collected on a $53 \mu \mathrm{m}$ sieve. The mesh size of the plankton sieves used was increased to 53 and 210 $\mu \mathrm{m}$ for $3.5-5 \mathrm{~mm}$ larvae, 125 and $350 \mu \mathrm{m}$ for $5-9 \mathrm{~mm}$ larvae, and 210 and $420 \mu \mathrm{m}$ for larvae greater than $9 \mathrm{~mm}$. Mean prey width was maintained at approximately $4 \%$ of larval SL. Prey composition consisted mainly of copepod nauplii and copepodites $(60 \%-80 \%)$ throughout the study period.

For all the species, the experiments encompassed the entire larval stage from just after the first feeding to pre-settlement (Table 1). We carried out experiments on the larvae of $P$. amboinensis and N. bankieri at 3-d intervals starting from $3 \mathrm{~d}$ post-hatch until just prior to settlement. As apogonid larvae do not display a prominent metamorphosis either in the laboratory or in the field (Brothers et al. 1983; Finn and Kingsford 1996), they were studied at 3-d intervals from $3 \mathrm{~d}$ post-hatch until they reached a size similar to that at which they first occur on coral reefs. Larvae of $P$. biaculeatus were studied at $2,4,5,6,7$, and $8 \mathrm{~d}$ post-hatch (they settled at approximately day 9) and A. melanopus at $2,4,5$, and $6 \mathrm{~d}$ post-hatch (settlement occurred at approximately day 7). Multiple batches of A. melanopus, N. bankieri, and $C$. quinquilineatus larvae were used for the experiments. As no batch differences were found, only one batch was reared for each of the four remaining species. The mean sizes and range of ages of all species at the end of the rearing program closely matched those recorded for field caught individuals (Table 2). This suggests that the effects of captive breeding and rearing had minimal effects on overall growth patterns. Furthermore, previous studies have suggested that there is also no difference in sensory morphology or behavior between the laboratory-reared and wild-caught larvae (Higgs and Fuiman 1998, and references therein). The abilities of the larvae in the present study, therefore, are 
Table 2. Age and size at settlement of field-caught and laboratory-reared fishes.

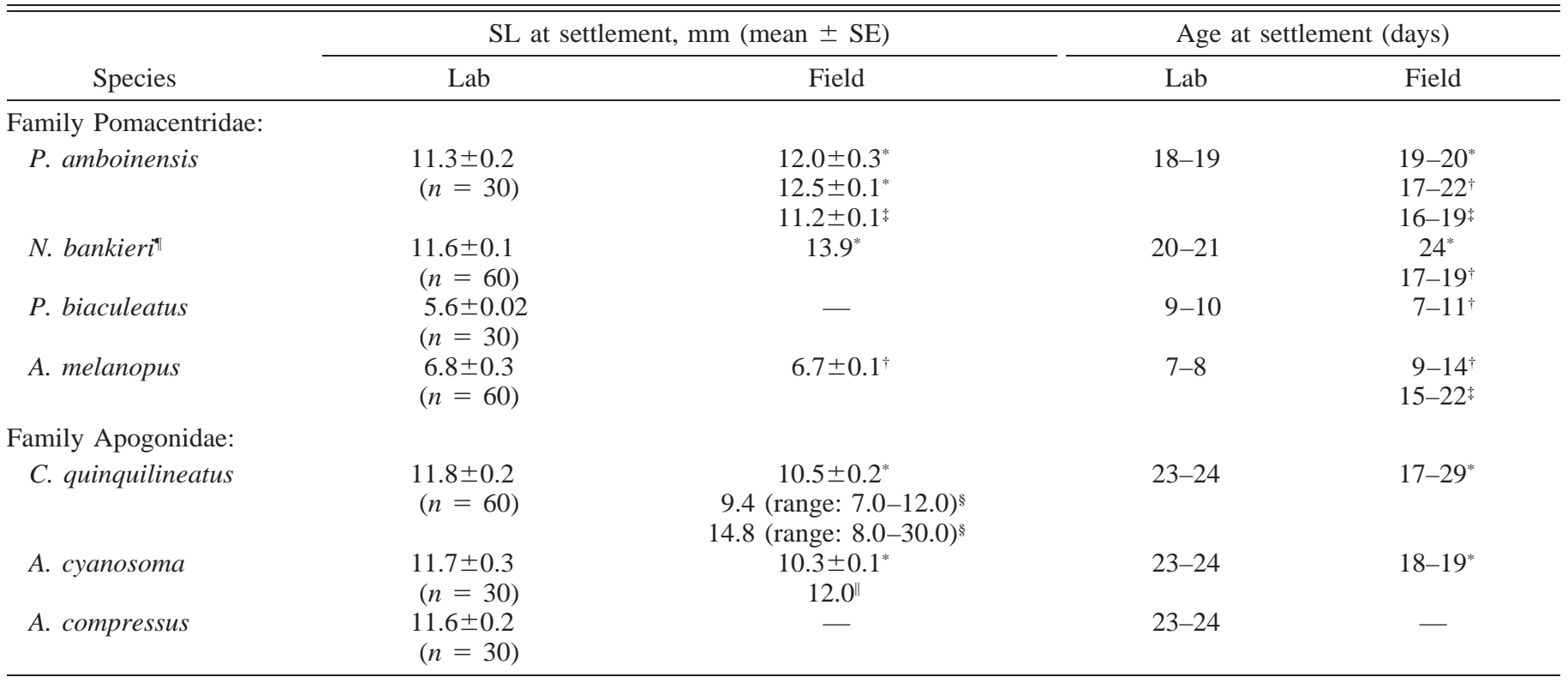

* Brothers et al. (1983).

$\dagger$ Thresher et al. (1989).

$\ddagger$ Wellington and Victor (1989).

$\S$ Finn and Kingsford (1996).

\| J. M. Leis, pers. comm.

II Field data for $N$. bankieri is based on the closely related N. azysron.

likely to be broadly comparable to those of larvae in the field.

The specific objective of the experiments was to determine the lowest light thresholds required for feeding. All experimental larvae had been deprived of food for at least $10 \mathrm{~h}$ (i.e., overnight). For each trial, a set of 10 larvae was placed

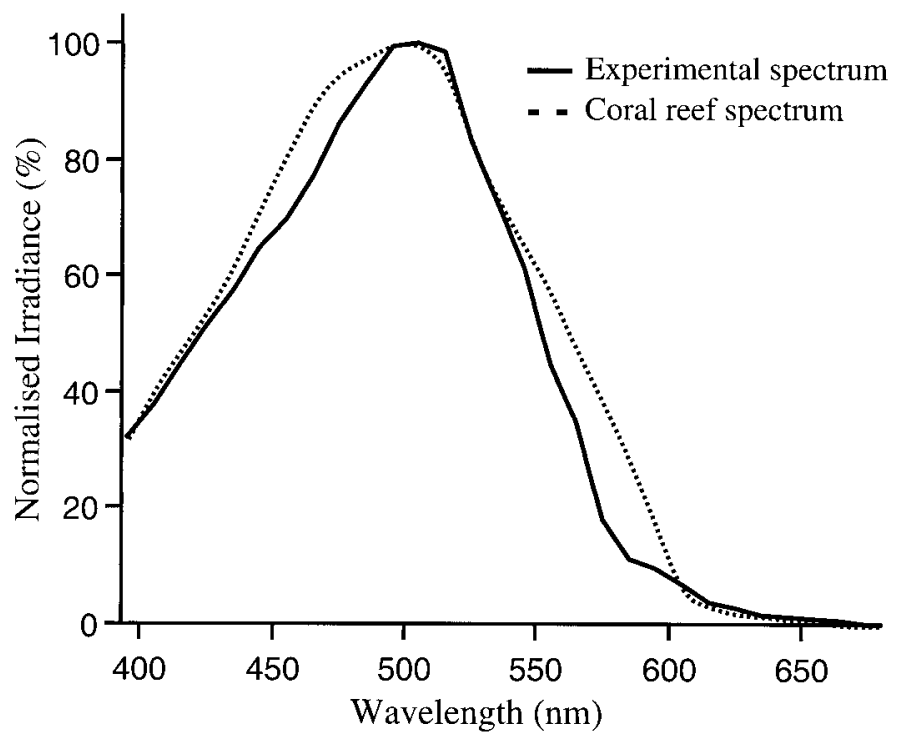

Fig. 1. Experimental spectral distribution vs. field values at approximately $25 \mathrm{~m}$ depth in coral reef waters. Spectral energy values have been normalised (i.e., as a $\%$ of $\lambda_{\max }$ ). Field values adapted from Lythgoe et al. 1995 and Maritorena and Guillocheau (1996). in a $170 \times 120 \times 120 \mathrm{~mm}$ experimental tank and their feeding behaviour observed using infrared video techniques (Fuiman and Delbos 1998). The experimental light spectrum (Fig. 1) approximates the light environment at moderate depths (20-30 m) during the day in clear coral reef waters (Lythgoe et al. 1994; Maritorena and Guillocheau 1996). The light spectrum at greater depths in the field would be slightly narrower (Jerlov 1976), but spectral attenuation at depths greater than $20 \mathrm{~m}$ would be limited in comparison with the attenuation at shallower depths. Experimental work was undertaken during daylight hours to avoid any anomalies caused by circadian rhythms. In experiments, the ten larvae were maintained in darkness for 45-60 min, then the light intensity was increased gradually to the minimum level sufficient to initiate positive phototaxis in the younger larvae and minimal movement in the older larvae. The larvae were maintained at this illumination level for a further 15-30 min prior to starting an experimental trial. Prey organisms (wildcaught zooplankton) were added to the experimental tank to a density of 1-2 per ml. Prey were scaled to larval size as in the rearing tanks (mean prey width approximately $4 \%$ of fish SL). Natural prey ensured that the larvae were presented with prey that displayed contrast levels and movement patterns that closely replicated those of prey in the field.

For each trial, the light intensity was increased in $0.3-\log$ unit increments at 15-min intervals using metallic-coated neutral density filters (these had no effect on spectral properties). When at least one larva began feeding (minimum of seven strikes at prey; strike $=$ feeding episode preceded by prey tracking), the light intensity was then reduced by one increment (0.3 log units) to determine whether feeding 
ceased. If larval feeding ceased, the light intensity was increased by one $0.3-\log$ unit increment to confirm the consistency of this threshold (i.e., whether feeding was again initiated at the adjacent higher light intensity). This process was repeated at least three times to ensure the consistency of this threshold. If feeding did not cease after a reduction of one increment, the light intensity was reduced incrementally until feeding ceased; this was invariably at the next increment. When feeding ceased, the light intensity was then increased by one increment to re-initiate feeding. This process was then repeated (i.e., reduced until feeding ceased and then increased until feeding was re-initiated) until a consistent light threshold for feeding was obtained (repeated at least three times). The minimum light intensity for feeding (functional sensitivity), therefore, was the lowest intensity at which a consistent feeding response (minimum of seven strikes) was initiated by at least one larva. For each species, three trials were conducted at each age for each batch of larvae. Each trial was conducted on a separate set of 10 larvae.

Light intensities down to $0.005 \mu \mathrm{E} \mathrm{m}^{-2} \mathrm{~s}^{-1}$ were measured at the water surface with a Li-Cor LI-192SA quantum sensor (400-700 $\mathrm{nm}$ range). Light intensities below $0.005 \mu \mathrm{E} \mathrm{m}^{-2}$ $\mathrm{s}^{-1}$ were outside the accurate range of the sensor and were extrapolated based on the measured characteristics of the neutral density filters. Depth equivalents were calculated by extrapolating from the quanta measurements for Oceanic Type II waters provided in Jerlov (1976), using a surface irradiance estimate of $1800 \mu \mathrm{E} \mathrm{m}^{-2} \mathrm{~s}^{-1}$. Jerlov Oceanic Type II waters are optically equivalent to those on the outer reefs of the Great Barrier Reef (Lythgoe et al. 1994). Field estimates for maximum daytime surface irradiance in tropical waters range from approximately $1200 \mu \mathrm{E} \mathrm{m}^{-2} \mathrm{~s}^{-1}$ (Michalek-Wagner, pers. comm.) to $2400 \mu \mathrm{E} \mathrm{m}^{-2} \mathrm{~s}^{-1}$ (Falkowski et al. 1990).

At the end of the trials, the larvae were anaesthetized by chilling, fixed in marine Bouin's fixative for $24 \mathrm{~h}$, and stored in $70 \%$ ethanol. The standard length, total length, eye, and lens diameters were measured on the stored larvae and the mean calculated for each set of 10 larvae. Shrinkage was estimated to be approximately $10 \%$ except for the lens diameter, where shrinkage was assumed to be negligible (cf. Job and Bellwood 1996). Measurements were adjusted for shrinkage prior to the analyses. As age-based and size-based measures of changes in functional abilities often portray different patterns, both measures are presented below. Ontogenetic (age-based) changes are arguably better represented by age-based scales as this reduces the impact of differential somatic growth rates. However, functional capabilities are often measured in relation to total somatic size or the size of the specific functional units, as these values are more easily measured in field-caught specimens. In our study, somatic size is represented by the mean SL, and the size of the primary functional unit by the mean eye and lens diameters. The eye diameter: lens diameter ratio was calculated for each individual as a proxy for the focal length: lens radius ratio (Matthiessen's ratio; van der Meer 1994) and the mean calculated for each set of 10 larvae.
Data analysis-The minimum light intensity for feeding data were transformed to a $\log _{10}$ scale (Lg Int). The relationships between $\mathrm{Lg}$ Int $\left(\log _{10}\right.$ minimum light intensity for feeding) and age (in days post-hatch), mean SL, mean eye diameter (ED), mean lens diameter (LD), and developmental age (DA) were assessed separately for each species. Developmental age is a modification of the Ontogenetic Length concept presented by Fuiman and Higgs (1997), which takes into account the fact that ontogenetic development begins from the point of egg fertilisation and largely stops after metamorphosis. As such, developmental age provides a standardized measure of the overall developmental status of the larvae and facilitates inter-taxon comparisons. Developmental age is calculated as:

$$
\begin{aligned}
\mathrm{DA}= & (\text { egg duration }+ \text { age at experiment }) \\
& \div(\text { egg duration }+ \text { larval duration })
\end{aligned}
$$

Analysis of covariance (ANCOVA) was used to compare minimum light intensities for feeding between the Apogonidae (all three species pooled) and the Pomacentrinae (both species pooled) with $\log _{10}$ (developmental age), $\log _{10}$ (mean eye diameter), and $\log _{10}$ (mean lens diameter) as the individual covariates. The amphiprionine species (Amphiprion melanopus and $P$. biaculeatus) were not included in this analysis as they had markedly shorter size ranges and larval durations, which only covered a small part of the range exhibited by the other two groups. In all analyses, the data were first assessed for linearity, normality, heteroscedasticity, and outliers using residual plots. In all cases, a $\log _{10}$ transformation of the independent variable was necessary to linearize the data and to satisfy the other assumptions of ANCOVA.

\section{Results}

Ontogenetic changes in functional sensitivity: age as a determinant of maximum feeding depth-All seven species showed a marked increase in sensitivity throughout the larval stage (Figs. 2, 3), with their relative abilities strongly reflecting familial or sub-familial groupings. At a given age post-hatch, the amphiprionine pomacentrids had the greatest sensitivity followed by the apogonids and with some overlap, the pomacentrine pomacentrids (Fig. 2). Immediately prior to settlement the estimated maximum feeding depth of about $170 \mathrm{~m}$ was comparable for both pomacentrid groups, despite the fact that larval duration in pomacentrine pomacentrids was more than twice that of the amphiprionine pomacentrids. For apogonids, the extended larval duration was marked by a proportional increase in sensitivity and a concomitant increase in the estimated maximum feeding depth to $200 \mathrm{~m}$ at the time of settlement.

When the data were evaluated using developmental age (which by definition lies between 0 and 1), the effect of an extended egg stage in amphiprionine pomacentrids is clearly apparent (Fig. 3). In terms of developmental age there is a marked difference between pomacentrids and apogonids, with apogonids being consistently about 1 log light unit more sensitive than pomacentrids. However, it was in the 


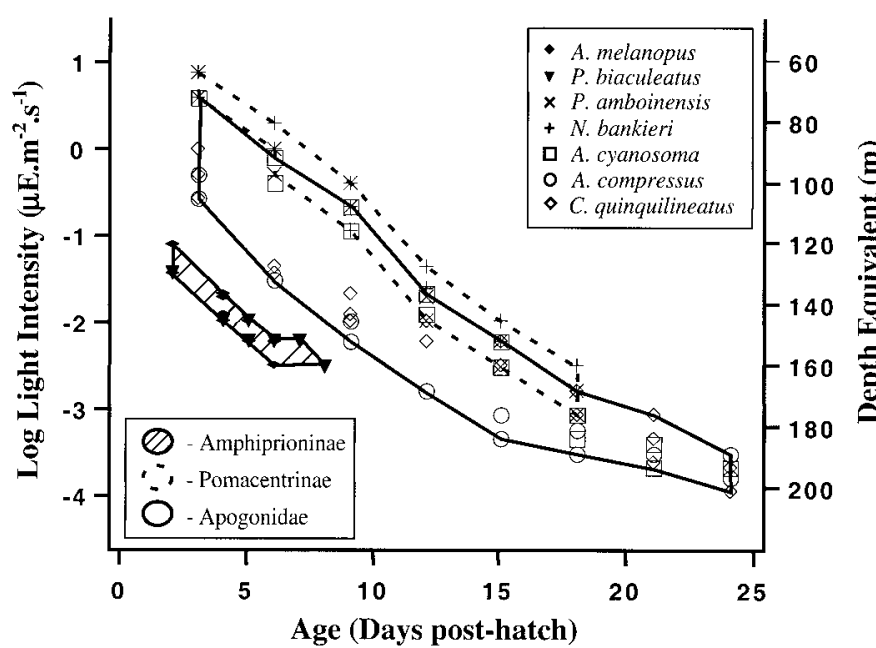

Fig. 2. Change in minimum light intensity for feeding with age (days post-hatch).

amphiprionine pomacentrids that the effect of post-hatch age vs. developmental age was most striking. On the basis of post-hatch age, the amphiprionine pomacentrids hatched in a relatively advanced state and increased sensitivity in a manner comparable to the other taxa. In terms of developmental age, however, the amphiprionine pomacentrids merely lay along the same developmental trajectory as the other pomacentrids. It appears that for both amphiprionine and pomacentrine pomacentrids, the development of visual sensitivity follows a relatively conservative schedule (trajectory), and that amphiprionine pomacentrids merely hatched at a much later stage than in pomacentrine pomacentrids.

Size and taxon-related changes in functional sensitivityChanges in visual sensitivity throughout ontogeny were similar for SL and eye diameter (Figs. 4, 5). For a given body size or eye size, the apogonids were about $1 \log$ unit more sensitive than pomacentrine pomacentrids. The amphiprionine pomacentrids were again relatively well developed in

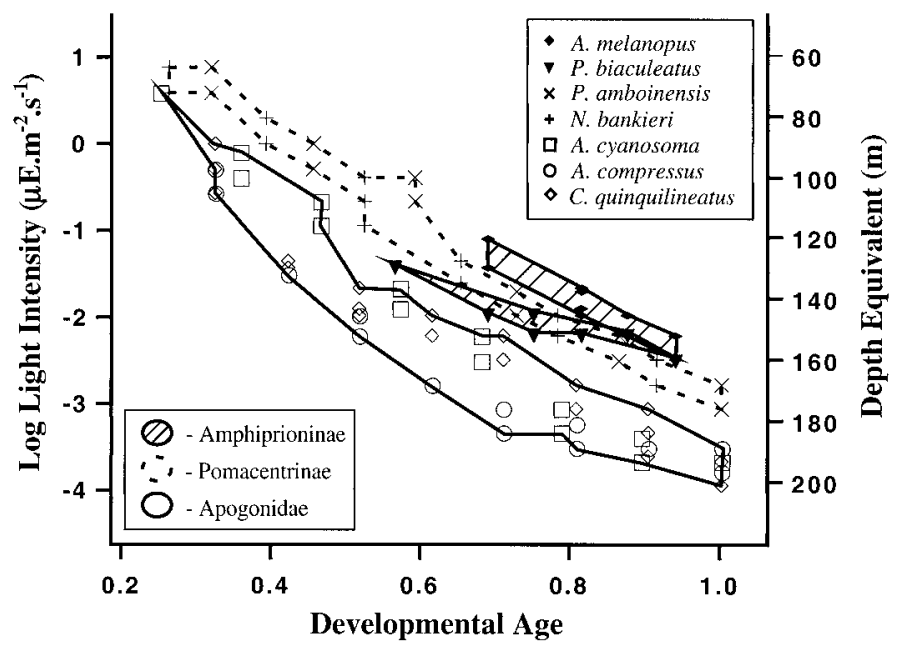

Fig. 3. Change in minimum light intensity for feeding with developmental age.

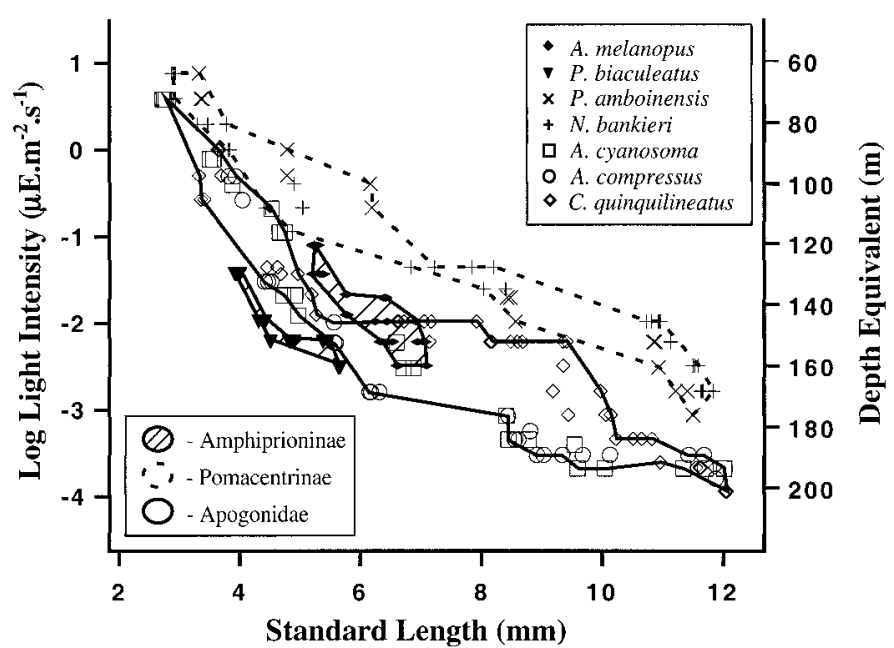

Fig. 4. Change in minimum light intensity for feeding with mean standard length.

comparison to the other pomacentrids and straddled the apogonids. It appears that although the amphiprionine pomacentrids followed the same developmental trajectory as other pomacentrids, they had a longer egg phase and hatched with relatively well developed small eyes and a small body. They achieved the respective stages at a younger age and with a small body and small eyes. These results indicate that light sensitivity is not simply dependant on eye size; other factors, possibly anatomical constraints within the eye, must also be involved.

The slopes of the change in minimum light sensitivity for the apogonids and pomacentrine pomacentrids were not significantly different regardless of whether the covariate was log developmental age, log eye diameter or log lens diameter (Table 3). In all cases, however, the intercepts were significantly different (Table 3 ). Thus, despite the apogonids having a consistently higher visual sensitivity, the two families displayed changes in sensitivity of a comparable magnitude with the same trajectory. In all taxa, the visual sensitivity and the realised feeding performance of larvae was strongly correlated with age, developmental age, body size, and eye

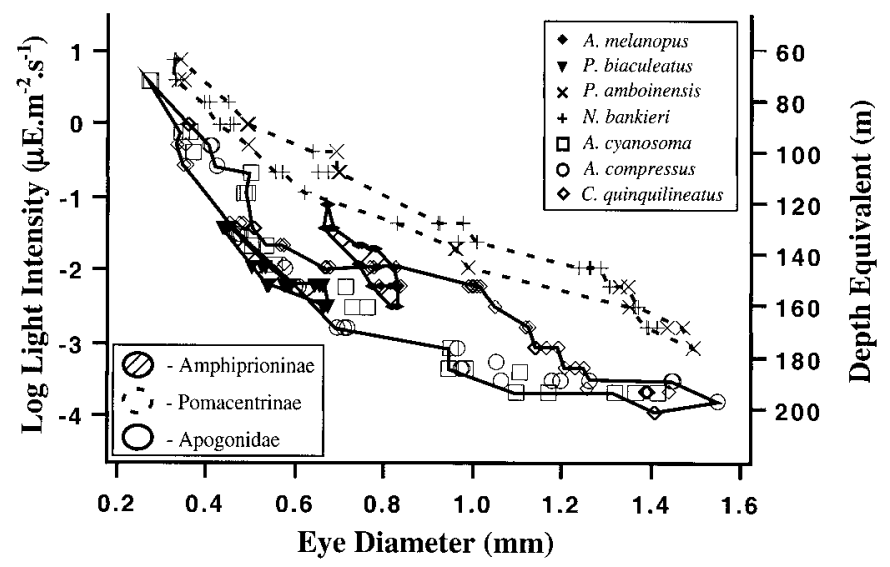

Fig. 5. Change in minimum light intensity for feeding with mean eye diameter. 
Table 3. Variation in visual sensitivity between the Apogonidae and Pomacentrinae. Data for species within a family or subfamily have been pooled; Analysis of Covariance based on $\log _{10}$ transformed data $(\mathrm{df}=1,146)$.

\begin{tabular}{lccc}
\hline $\begin{array}{l}\text { Param- } \\
\text { eter }\end{array}$ & $\begin{array}{c}\text { log developmental } \\
\text { age }\end{array}$ & $\begin{array}{c}\text { log eye } \\
\text { diameter }\end{array}$ & $\begin{array}{c}\text { log lens } \\
\text { diameter }\end{array}$ \\
\hline Slope & $F=1.62$ & 1.81 & 0.95 \\
& $p=0.21$ & 0.18 & 0.33 \\
Intercept & $F=373.28$ & 467.37 & 309.65 \\
& $p=<0.0001$ & $<0.0001$ & $<0.0001$ \\
\hline
\end{tabular}

size. In each case, the developmental trajectories were highly conservative and all taxa showed a consistent relationship between measures of size or age, and ability. However, at any point, the major factor that determined the relative sensitivity of a larva was its phylogenetic association. The basis for these differences is unclear, although differences in the Matthiessen's ratio were consistent with the observed patterns (Fig. 6).

\section{Discussion}

Feeding performance and larval fish distributions-We examined the functional light sensitivity of fish larvae under experimental conditions. This information provides an empirical basis for examining the performance capabilities of fish larvae and provides data that may be considered in a broader ecological context. The measurements taken represent the minimum light intensity at which feeding is possible. It is therefore a functional performance measure for feeding and not an absolute measure of simple light perception. Thus, we suggest that these results may be directly applicable to field conditions. The values recorded were the light levels at which a complete feeding sequence was recorded, not simply the prey detection. In a complete feeding sequence the fish must: (1) detect potential prey, (2) distinguish ingestible prey items, (3) track the mobile prey, and (4) have sufficient stimulation to elicit a feeding response (a strike). The utility of this performance measure is maximized by examining feeding on recently collected natural prey, under light spectra that closely match field values, using larvae conditioned to the wild-caught prey. The results may therefore provide a reasonable approximation of realised abilities in the field. Our study shows that fish larvae display substantial ontogenetic and taxonomic differences in the minimum light levels required to feed on natural prey items. A clear understanding of the role of light intensity in structuring vertical distribution patterns is central to our understanding of the ecology of larval fishes and needs to be based on knowledge of the functional sensitivity of the larvae throughout ontogeny.

It must be noted that the change in sensitivity in the larvae in our study is probably a result of changes in both the functional sensitivity of the visual system and the size of prey items. Larger prey items would be visible at lower light intensities (Blaxter 1968; Batty et al. 1990) and therefore, larger larvae may inherently be able to feed at lower light intensities than smaller larvae. However, a similar change in

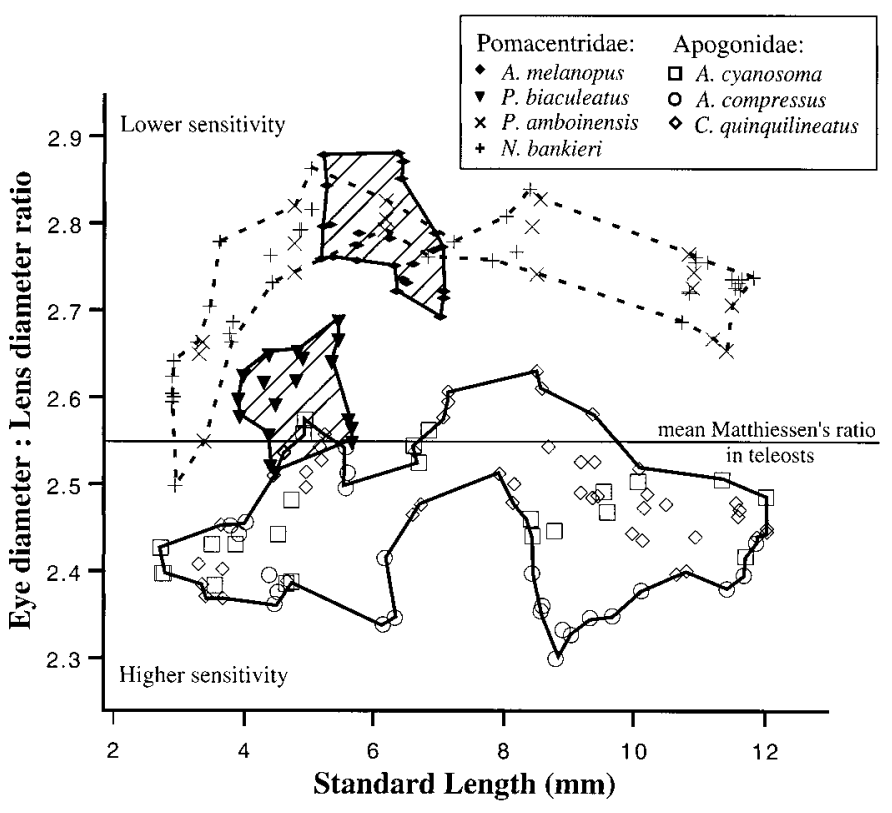

Fig. 6. Interspecific variation in the mean ratio of eye diameter to lens diameter (estimate of Matthiessen's ratio). The line at the eye diameter: lens diameter value of 2.55 indicates the mean Matthiessen's ratio value for teleost fishes (after Fernald 1988). Lower values indicate eyes with greater light sensitivity.

prey size in the studies of Blaxter (1968) and Batty et al. (1990), where fish size was constant, resulted only in an increase in light sensitivity of approximately 1 order-of-magnitude. The magnitude of the change in functional sensitivity in the present study (3-4 orders-of-magnitude), therefore, suggests that the increase in light sensitivity is driven primarily by changes in the visual system. As the size of prey eaten by larval fishes increases in the field during ontogeny (reviewed in Gerking 1994), the gradient in prey sizes used in this study provide values that are directly applicable to field conditions.

Ontogenetic and somatic constraints on vertical zonation in fish larvae-The majority of field studies investigating larval vertical distribution patterns suggest that older larvae are generally found deeper in the water column than younger larvae (Munk et al. 1989; Boehlert et al. 1992; but see Leis 1991b). One reason for this change in depth preference could be that as the larvae grow, they are able to feed successfully in a better way at greater depths. As older copepod stages are often found at deeper depths (Munk et al. 1989; Falkenhaug et al. 1997), this would allow the larvae to utilize larger prey. The larvae in our study underwent changes in light sensitivity of more than 3 orders-of-magnitude from early feeding to pre-settlement, with a corresponding increase in the potential maximum depth for visual feeding. Older larvae therefore, would have far greater flexibility to modify their depth distribution, either to avoid predation or to seek areas of greater prey abundance. It seems likely that increasing sensory capabilities and somatic size will work in concert to allow older larvae to not only capture and ingest larger prey but also to select strata that contain higher den- 
sities of these prey items. Larval fishes are, therefore, a potentially heterogeneous group even within a species and may display marked ontogenetic niche shifts within the pelagic environment.

The observed changes in feeding performance add a new dimension to the prey availability hypotheses. Younger larvae may remain at shallower depths owing to limitations imposed by their light sensitivity. They are incapable of feeding at greater depths. Changes in prey type and predation risk (Fortier and Harris 1989), may simply be a consequence of this constraint. Our results may also resolve an apparent anomaly in the data of Munk et al. (1989). These authors noted a correlation between the distribution of the larger larvae and their prey. However, there was no correlation between the distribution of prey and the smallest size class of larvae, which were always distributed at shallower depths. As these authors used the same estimate for the light intensity threshold for feeding behaviour in all sizes of larvae, the lack of a correlation in the youngest larvae may merely have been a result of their limited visual abilities.

The potential depth maxima presented in our study are the depths beyond which visual feeding ceases. However, it is unlikely that fish will feed at these threshold limits as visual resolution and prey detection distances are generally low at the limits of light sensitivity (Blaxter 1988; Utne 1997). A more likely scenario is one in which there are a number of trade-offs. Going deeper into the water column may result in a greater feeding efficiency due to greater prey abundance until the point at which the light intensity reduces the reaction distance (maximum distance at which prey can be detected) and thus, the prey location ability. Beyond that point, the benefit of increased prey abundance would be offset by a decreased ability to locate prey. We envisage a shallower pattern of preferred feeding depths compared with the maximum feeding depths. Light intensity ceases to limit reactive distance about 1-2 orders-of-magnitude above the feeding threshold (Blaxter 1988; Utne 1997). Taking a conservative value of 2 orders-of-magnitude, one can calculate unconstrained feeding depths, i.e., depths at which light levels are unlikely to limit feeding behavior. These depths (Fig. 7) suggest that there would be a considerable potential for vertical stratification in the upper $100 \mathrm{~m}$, particularly in younger larvae. The presence of such size and taxon-specific depth distributions in young larvae (Leis 1991b; Cowen and Castro 1994) suggests that vision may play a role in determining larval distributions even in shallow waters and that unconstrained feeding depths may provide a better explanation for distribution patterns than threshold maxima. It should be noted that data on larval distributions in the field are generally obtained using ichthyoplankton tows, which selectively capture younger larvae, especially pre-flexion larvae (Choat et al. 1993). The field vertical distribution patterns of older larvae are less well known. Given the relatively high light sensitivity of the older stages, their potential foraging depths are relatively deep $(200 \mathrm{~m})$. Even allowing for variation in water clarity, the late stage larvae within continental seas would be capable of feeding throughout the water column (Fig. 7). At this stage, factors other than light may become increasingly important in depth selection.

This potential for feeding at great depth has important

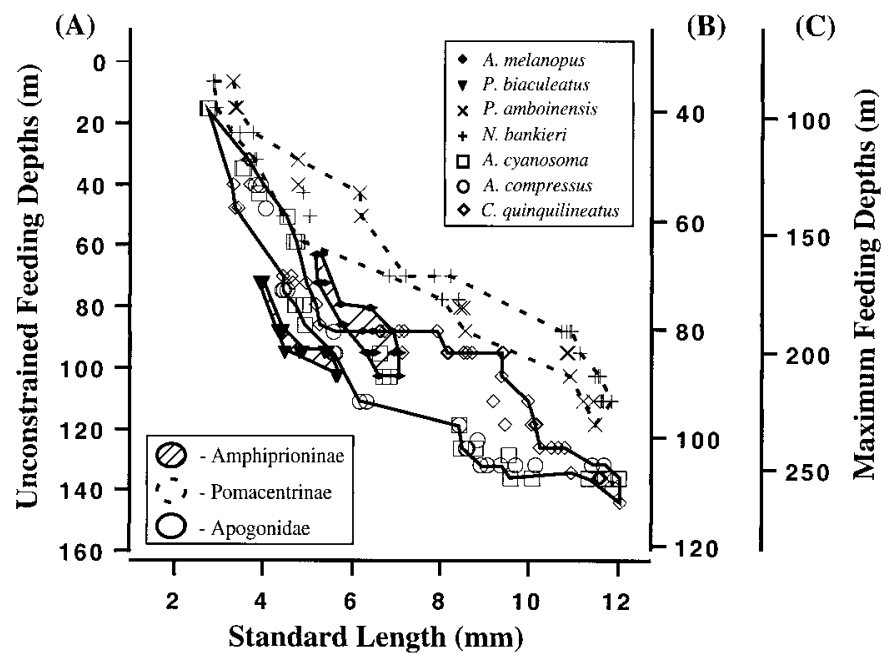

Fig. 7. Variability in feeding depths. (A) Unconstrained feeding depths. On the basis of light intensities 2 orders-of-magnitude greater than the feeding threshold in Jerlov Oceanic Type II waters. This gives the approximate depths where feeding is not limited by light levels. (B) Maximum feeding depths in eutrophic coastal waters (Jerlov Coastal Type 1 waters). (C) Maximum feeding depths in clear oceanic waters (Jerlov Oceanic Type IB waters).

ramifications in numerous areas of larval fish biology. It provides late stage larvae with access to a wider range of food resources and may provide a refuge from visually mediated (fish-based) predation (Clark and Levy 1988). However, one of the greatest impacts may be on dispersal capabilities as it enables the larvae to access deep currents for prolonged periods. In reef fishes, dispersal is largely restricted to the few days or weeks that the larvae spend in the plankton, with the late larval stage being a critical period in their return to reefs (Stobutzki and Bellwood 1997). One of the key questions in the discussion of dispersal patterns is the extent to which these patterns are dependent upon surface circulation currents (see Hare and Cowen 1996; Roberts 1997). Given maximum feeding depths of 60-200 m, models relying on surface currents may be misleading. Deep currents often flow in a direction different to surface currents, and vertical migration may provide a mechanism for enhancing or restricting dispersal by access to these differential current regimes (Cowen and Castro 1994). Such deep currents (50$200 \mathrm{~m}$ ) have been implicated in the dispersal of a number of marine taxa (Scheltema 1986), and in shelf systems there is a strong possibility that deep onshore currents may enhance larval retention (Cowen and Castro 1994).

Although the swimming abilities of young reef fish larvae are yet to be described, the progressive increase in visual capabilities of larvae during ontogeny would permit sustained access to water of increasing depth. During development, reef fish larvae would become increasingly able to influence their dispersal patterns not only by horizontal swimming (cf. Stobutzki and Bellwood 1997) but also by vertical migration, accessing an increasingly large range of depths and associated current regimes. In continental waters, this may include the seabed boundary layer; this ability may be used to enhance or retard dispersal. A comparable strat- 
egy to avoid advection from estuaries has been recorded in coastal taxa (Laprise and Dodson 1989). Access to deeper waters may permit pre-settlement larvae to actively return to the reef of origin or to hold station near to a reef until the appropriate settlement time (e.g., the new moon). Vertical migration may offer an energetically efficient mechanism for avoiding advection.

Phylogenetic constraints on vertical zonation-The quantitative difference in visual sensitivity only provides a crude estimate of the difference between taxa in terms of depth equivalents as it would vary in the field depending on a range of factors such as the light attenuation characteristics of different water bodies (Fig. 7), and surface irradiance levels. What is more important is the relative abilities of the larvae and the nature of the differences between taxa. Leis (1991b) noted that related taxa display similar vertical distribution patterns in the field and that pomacentrid larvae are found at shallower depths than apogonid larvae, with apogonid larvae showing a broader depth distribution pattern. This pattern correlates well with the inter-taxon differences in visual sensitivity observed in this study (Figs. 2-5). Boehlert et al. (1992) likewise found consistent differences between families. Apogonid species were recorded at depths of at least $200 \mathrm{~m}$ (the deepest stratum sampled) and generally showed peak abundances in the deeper strata $(50-100 \mathrm{~m}$ and 100-200 m). In contrast, pomacentrid larvae had higher abundances in the shallowest depth stratum $(0-50 \mathrm{~m})$. Boehlert et al. (1992) sampled larvae at night and whilst the distributions may not accurately depict daytime patterns, they may provide a better sample of older larvae, which may be capable of net avoidance during the day (Choat et al. 1993). Our results suggest that the taxon-specific preferred light levels that have been proposed as a major influence on the vertical distribution patterns of larvae (Blaxter 1988; Leis 1991a) may be a result of inter-taxon differences in functional visual abilities.

Functional constraints in the development of the visual system-While the change in light sensitivity with growth and development appears to be primarily driven by increasing somatic size, the consistent difference between taxa at similar eye sizes (Fig. 5) indicates that the overall size of the eye is only one of the factors determining visual sensitivity. One factor that may be important in determining interspecific differences in sensitivity is Matthiessen's ratio (focal length: lens radius), which was estimated from the ratio of eye diameter to lens diameter (van der Meer 1994). A lower focal length:lens radius ratio may be an effective mechanism for increasing retinal illumination (McFarland 1991). The low ratio in apogonids indicates that they allow more light to reach the retina than in pomacentrid eyes of similar size (Fig. 6). This difference in Matthiessen's ratio may underlie the familial difference in functional sensitivity. Changes in visual sensitivity in larval fishes may be a result of both an increase in eye size and ontogenetic changes, i.e., the appearance of new cell types and changes in neural circuitry (Fuiman and Delbos 1998; Higgs and Fuiman 1998). The consistent nature of the change in functional sensitivity in all species suggests that either all species had a rigid de- velopmental schedule with a gradual increase in the density of new types of photoreceptors, or that the increase in functional sensitivity is more dependent on the increase in magnitude of some component within the eye and that this change overshadows the impact of the appearance of new cell types. For example, van der Meer (1994) has shown that changes in photopic (cone-based) light sensitivity in juvenile fishes is strongly correlated with increasing cone size.

One of the most striking features of the data is the consistent pattern in the pomacentrine pomacentrids and the apogonids. Despite a 1 order-of-magnitude difference in functional sensitivity, the slopes of the developmental trajectories are almost identical. These similarities are maintained regardless of the scale used. It is not simply a case of pomacentrids having proportionally smaller eyes. This pattern suggests that regardless of family, the ontogenetic change in the visual system follows a similar set pattern independent of overall eye size. What is most striking about the inter-family difference is that it is established from the earliest stages of life. Even with a rudimentary visual system at first feeding, apogonids are already almost 1 order-ofmagnitude more sensitive than pomacentrids. The different diurnal activity patterns of adult apogonids and pomacentrids are reflected in marked differences in the visual systems of the adults (Helfman 1993). Settlement has frequently been viewed as the stage during which reef fishes first begin to manifest many adult adaptations and abilities. It now appears that some differences in the functional abilities of the visual systems of these two families are established in the early stages of the larval phase rather than as a prelude to assuming the adult habit.

The consistent similarities between more closely related species and the difference between the two families suggest that there is a strong phylogenetic basis underlying the visual sensitivities of the various species. However, while the relationship between the apogonids and the pomacentrine pomacentrids do not change markedly between somatic and developmental age scales, the status of the amphiprionine pomacentrids changes dramatically. This would seem to suggest that while ontogenetic developmental schedules may differ little between the pomacentrine pomacentrids and the apogonids, the amphiprionine pomacentrids (anemonefishes) are following a different developmental strategy. The anemonefishes are unusual in that their egg duration is much longer than that of the other pomacentrids and their larval duration much shorter. They appear to have modified the pomacentrine pomacentrid pattern by undertaking extensive development prior to hatching with ontogenetic development being accelerated to achieve a similar stage of development at a smaller somatic size. Thus, at a given stage in development (by developmental age), the pomacentrine pomacentrids, and the amphiprionine pomacentrids possess similar abilities despite marked differences in size (Fig. 8).

The reason for settlement at a small size in anemonefishes is unclear. However, we suggest that it may be related to the nature of the settlement site and associated mortality rates. Anemonefishes settle directly into an anemone and probably experience lower mortality rates during the vulnerable first few days or weeks on the reef. For these taxa size at settlement may be relatively unimportant, although sensory, and 

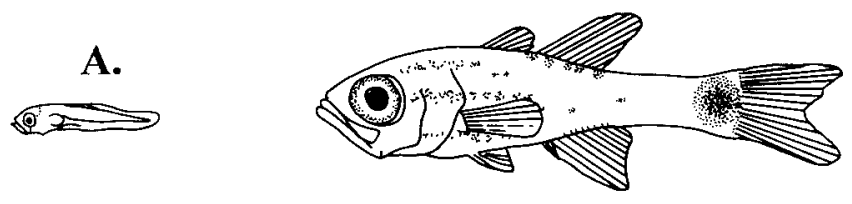

B.

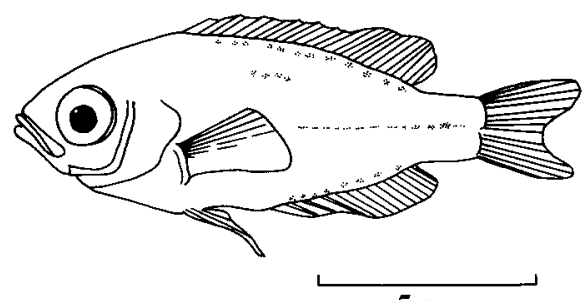

C.

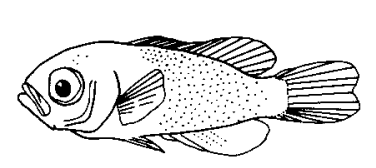

$5 \mathrm{~mm}$

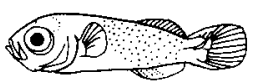

Fig. 8. Development in representative taxa. (A) Apogon compressus (Day 3 and Day 23 post-hatch), (B) Pomacentrus amboinensis (Day 3 and Day 17 post-hatch), (C) Amphiprion melanopus (Day 2 and Day 6 post-hatch). The two sizes approximate initial feeding and size immediately prior to settlement. All drawn to the same scale.

locomotor capabilities are critical to permit the detection and orientation to the highly restricted settlement site, the anemone. We hypothesize that fish settling into small but protected habitats (e.g., anemones and corals) are likely to experience relatively low rates of post-settlement mortality and are able to settle at a relatively small size. However, given the need for sensory and locomotor development, we hypothesize that this small size will arise through the production of precocial larvae rather than simply settling at an early stage of development. Consequences of this developmental strategy may include a prolonged embryonic development in the egg and a reduction in the length of the pelagic dispersal phase.

\section{Conclusion}

Our study provides a new perspective on the vertical distribution patterns and abilities of fish larvae, with both ontogeny and phylogenetic history having a major role in determining the maximum potential feeding depths. The pelagic environment on the scale of a larval fish is a heterogeneous environment in terms of light intensity and spectrum, prey distribution, and temperature gradients. Our understanding of the functional performance capabilities of larval fishes is central to our interpretation of the biological implications of physical structure within the pelagic environment. Several factors remain to be determined: how the larvae respond to ontogenetic changes in spectral sensitivity, the relationship between modal, mean, and maximum feeding depths and the structural features which underlie the observed functional differences. Our results highlight the need for both age and taxon-specific examinations of larval populations. Early post-hatch fish larvae can no longer be re- garded as a functionally uniform component of the planktonic community. However, despite the need for increased resolution, several unifying trends are apparent. Within a given family or subfamily functional abilities are broadly comparable and developmental trajectories appear to be highly conserved even between families. Thus it may be possible to provide a description of the relative capabilities of taxa using data from a limited number or taxa or developmental stages, providing a broad basis for the evaluation of the role of functional visual capabilities in the structuring and depth stratification of open water planktonic communities.

\section{References}

Batty, R. S., J. H. S. Blaxter, And J. M. Richard. 1990. Light intensity and the feeding behaviour of herring, Clupea harengus. Mar. Biol. 107: 383-388.

Blaxter, J. H. S. 1968. Visual thresholds and spectral sensitivity of herring larvae. J. Exp. Biol. 48: 39-53.

1988. Sensory performance, behaviour, and ecology of fish. p. 203-232. In J. Atema, R. R. Fay, A. N. Popper, and W. N. Tavolga [eds.], Sensory Biology of Aquatic Animals. SpringerVerlag.

Boehlert, G. W., W. Watson, And L. C. Sun. 1992. Horizontal and vertical distributions of larval fishes around an isolated oceanic island in the tropical Pacific. Deep-Sea Res. 39: 439466.

Brothers, E. B., D. McB. Williams, and P. F. SAle. 1983. Length of larval life in twelve families of fishes at One Tree Lagoon, GBR, Australia. Mar. Biol. 76: 319-324.

Choat, J. H., P. J. Doherty, B. A. Kerrigan, And J. M. Leis. 1993. A comparison of towed nets, purse seines, and light aggregation devices for sampling larvae and pelagic juveniles of coral reef fishes. Fish. Bull. 91: 195-209.

Clark, C. W., AND D. A. Levy. 1988. Diel vertical migrations by juvenile sockeye salmon and the antipredation window. Am. Nat. 131: 271-290.

Cowen, R. K., AND L. R. CASTRo. 1994. Relation of coral reef fish larval distributions to island scale circulation around Barbados, West Indies. Bull. Mar. Sci. 54: 228-244.

- J. A. HARE, AND M. P. FAHAY. 1993. Beyond hydrography: Can physical processes explain larval fish assemblages within the Middle Atlantic Bight. Bull. Mar. Sci. 53: 567-587.

DagG, M. J., B. W. Frost, And J. A. Newton. 1997. Vertical migration and feeding behaviour of Calanus pacificus females during a phytoplankton bloom in Dabob Bay, U.S. Limnol. Oceanogr. 42: 974-980.

Falkenhaug, T., K. S. Tande, and T. Semenova. 1997. Diel, seasonal and ontogenetic variations in the vertical distributions of four marine copepods. Mar. Ecol. Prog. Ser. 149: 105-119.

Falkowski, P. G., P. L. Jokiel, AND R. A. KinZIE III. 1990. Irradiance and corals. p. 89-107. In Z. Dubinsky [ed.], Ecosystems of the world, vol. 3: Coral Reefs. Elsevier.

Fernald, R. D. 1988. Aquatic adaptations in fish eyes. p. 435-466. In J. Atema, R. R. Fay, A. N. Popper, and W. N. Tavolga [eds.], Sensory Biology of Aquatic Animals. Springer-Verlag.

FinN, M. D., AND M. J. KingSFORD. 1996. Two-phase recruitment of Apogonids (Pisces) on the GBR. Aust. J. Mar. Freshw. Res. 47: 423-432.

FORTIER, L., AND R. P. HARRIS. 1989. Optimal foraging and densitydependent competition in marine fish larvae. Mar. Ecol. Prog. Ser. 51: 19-33. 
Fuiman, L. A. AND D. M. HigGs. 1997. Ontogeny, growth and the recruitment process. p. 225-249. In R. C. Chambers and E. A. Trippel [eds.], Early life history and recruitment in fish populations. Chapman and Hall.

Fuiman, L. A., AND Delbos, B. C. 1998. Developmental changes in visual sensitivity of red drum, Sciaenops ocellatus. Copeia 1998: 936-943.

Gerking, S. D. 1994. Feeding ecology of fish. Academic Press.

GronkJaer, P., AND K. Wieland. 1997. Ontogenetic and environmental effects on vertical distribution of cod larvae in the Bornholm Basin, Baltic Sea. Mar. Ecol. Prog. Ser. 154: 91105.

Haldorson, L., M. Prichett, A. J. Paul, And D. Ziemann. 1993. Vertical distribution and migration of fish larvae in a Northeast Pacific bay. Mar. Ecol. Prog. Ser. 101: 67-80.

Hare, J. A., AND R. K. Cowen. 1996. Transport mechanisms of larval and pelagic juvenile bluefish (Pomatomus saltatrix) from South Atlantic Bight spawning grounds to Middle Atlantic Bight nursery habitats. Limnol. Oceanogr. 41: 1264-1280.

Helfman, G. S. 1993. Fish behaviour by day, night, and twilight. p. 479-512. In T. J. Pitcher [ed.], Behaviour of Teleost Fishes, 2nd edn. Chapman and Hall.

Higgs, D. M., AND L. A. Fuiman. 1998. Associations between sensory development and ecology in three species of clupeoid fish. Copeia 1998: 133-144.

Jerlov, N. G. 1976. Marine optics. Elsevier.

JoB, S. D., AND D. R. BELlwoOd. 1996. Visual acuity and feeding in larval P. biaculeatus. J. Fish Biol. 48: 952-963.

- M. ARvedLund, AND M. MARnANe. 1997. Culture of Coral Reef Fishes. Austasia Aquaculture 11: 56-59.

LAPRISE, R., AND J. J. DODSON. 1989. Ontogeny and importance of tidal vertical migrations in the retention of larval smelt $\mathrm{Os}$ merus mordax in a well-mixed estuary. Mar. Ecol. Prog. Ser. 55: $101-111$.

LEIS, J. M. 1991a. The pelagic stage of reef fishes: The larval biology of coral reef fishes. p. 183-230. In P. F. Sale [ed.], The Ecology of Fishes on Coral Reefs. Academic Press.

- 1991b. Vertical distribution of fish larvae in the GBR lagoon, Australia. Mar. Biol. 109: 157-166.

LitvaK, M. K., AND W. C. LegGetT. 1992. Age and size-selective predation on larval fishes: The bigger-is-better hypothesis revisited. Mar. Ecol. Prog. Ser. 81: 13-24.

Lythgoe, J. N., W. R. A. Muntz, J. C. Partridge, J. Shand, And D. MCB. Williams. 1994. The ecology of the visual pigments of snappers (Lutjanidae) on the Great Barrier Reef. J. Comp. Physiol. A 174: 461-468.

Maritorena, S., and N. Guillocheau. 1996. Optical properties of water and spectral light absorption by living and non-living particles, and by yellow substances in coral reef waters of French Polynesia. Mar. Ecol. Prog. Ser. 131: 245-255.

MCFARLAND, W. N. 1991. The visual world of coral reef fishes, p. 16-38. In P. F. Sale [ed.], The Ecology of Fishes on Coral Reefs. Academic Press.

MeER V. D., H. J. 1994. Ontogenetic change of visual thresholds in the Cichlid fish Haplochromis sauvagei. Brain Behav. Evol. 44: 40-49.

Megard, R. O., M. M. Kuns, M. C. Whiteside, And J. A. DownING. 1997. Spatial distributions of zooplankton during coastal upwelling in western Lake Superior. Limnol. Oceanogr. 42: 827-840.

Munk, P., T. Kiorboe, And V. Christensen. 1989. Vertical migrations of herring, Clupea harengus, larvae in relation to light and prey distributions. Env. Biol. Fish 26: 87-96.

NeILson, J. D., AND R. I. Perry. 1990. Diel vertical migrations of marine fishes: An obligate or facultative process? Adv. Mar. Biol. 26: 115-168.

Nesbitt, L. M., H. P. Riessen, and C. W. Ramcharan. 1996. Opposing predation pressures and induced vertical migration responses in Daphnia. Limnol. Oceanogr. 41: 1306-1311.

Olivar, M. P., AND A. SAbates. 1997. Vertical distribution of fish larvae in the north-west Mediterranean Sea in spring. Mar. Biol. 129: 289-300.

Roberts, C. M. 1997. Connectivity and management of Caribbean coral reefs. Science 278: 1454-1457.

SCHeltema, R. S. 1986. On dispersal and planktonic larvae of benthic invertebrates: An eclectic overview and summary of problems. Bull. Mar. Sci. 39: 290-322.

StobutzKi, I., AND D. R. Bellwood. 1997. Sustained swimming abilities of the late pelagic stages of coral reef fishes. Mar. Ecol. Prog. Ser. 149: 35-41.

Thresher, R. E., P. L. Colin, And L. J. Bell. 1989. Planktonic duration, distribution, and population structure of Western and Central Pacific damselfishes (Pomacentridae). Copeia 1989: $420-434$.

Utne, A. C. W. 1997. The effect of turbidity and illumination on the reaction distance and search time of the marine planktivore, Gobiosculus flavescens. J. Fish Biol. 50: 926-938.

Wellington, G. M., AND B. C. Victor. 1989. Planktonic larval duration of one hundred species of Pacific and Atlantic damselfishes (Pomacentridae). Mar. Biol. 101: 557-567.

Williams, A., AND J. A. Koslow. 1997. Species composition, biomass, and vertical distribution of micronekton over the midslope region off southern Tasmania, Australia. Mar. Biol. 130: $259-276$.

Received: 7 April 1999 Accepted: 1 September 1999 Amended: 23 September 1999 